Article

\title{
Elucidating the dominant reaction mechanism of methanol-to-olefins conversion in H-SAPO-18: A first-principles study
}

\author{
Chuan-Ming Wang *, Yang-Dong Wang, Zai-Ku Xie \# \\ State Key Laboratory of Green Chemical Engineering and Industrial Catalysis, SINOPEC Shanghai Research Institute of Petrochemical Technology, \\ Shanghai 201208, China
}

\section{A R T I C L E I N F O}

\section{Article history:}

Received 18 January 2018

Accepted 21 March 2018

Published 5 July 2018

\section{Keywords:}

Methanol-to-olefins conversion

Hydrocarbon pool reaction mechanism

Olefin-based hydrocarbon pool

Density functional theory

H-SAP0-18 zeotype

\begin{abstract}
A B S T R A C T
The reaction mechanism of zeolite- or zeotype-catalyzed methanol-to-olefins (MTO) conversion is still a subject of debate. Employing periodic density functional theory calculations, the olefin-based cycle was studied using tetramethylethene (TME) as a representative olefinic hydrocarbon pool in H-SAPO-18 zeotype. The overall free energy barrier at $673 \mathrm{~K}$ was calculated and found to be less than $150 \mathrm{~kJ} / \mathrm{mol}$ in the TME-based cycle, much lower than those in the aromatic-based cycle $(>200$ $\mathrm{kJ} / \mathrm{mol}$ ), indicating that olefins themselves are the dominant active hydrocarbon pool species in H-SAPO-18. The similarity of the intermediates involved between the aromatic-based cycle and the olefin-based cycle was also highlighted, revealing that both cycles were pattern-consistent. The selectivity related to the distribution of cracking precursors, such as higher olefins or carbenium ions, as a result of the olefin-based cycle for the MTO conversion. The enthalpy barrier of the cracking step scaled linearly with the number of carbon atoms of cracking precursors to produce ethene or propene with ethene being much less favored than propene for cracking of C7 and higher precursors. This work highlighted the importance of the olefin-based cycle in H-SAPO-18 for the MTO conversion and established the similarity between the olefin-based and aromatic-based cycles.
\end{abstract}

(C) 2018, Dalian Institute of Chemical Physics, Chinese Academy of Sciences. Published by Elsevier B.V. All rights reserved.

\section{Introduction}

Production of light olefins (ethene, propene, and butenes) from $\mathrm{C} 1$ building blocks such as syngas $\left(\mathrm{CO}+\mathrm{H}_{2}\right)$ is highly significant because it provides a promising alternative to form bulk chemicals from nonpetroleum resources like coal, natural gas, biomass, and $\mathrm{CO}_{2}[1,2]$. Among these processes, the methanol-to-olefins conversion (MTO), first developed four decades ago, has attracted broad attention and has now been commer- cialized in China [3-6]. Methanol can be commercially synthesized from syngas using $\mathrm{Cu}-\mathrm{ZnO}-\mathrm{Al}_{2} \mathrm{O}_{3}$ as a catalyst [7]. Porous silicoaluminophosphate (SAPO) zeotypes with eight-membered pores and moderate cages have been demonstrated as the most efficient catalysts for the MTO conversion, with high selectivity to ethene and propene [8-10]. H-SAPO-34 with a CHA topology structure exhibits high catalytic activity and selectivity for MTO conversion, which has been extensively investigated by both academic and industrial communities [11]. In addition,

\footnotetext{
* Corresponding author. Tel: +86-21-68462197; Fax: +86-21-68462283; E-mail: wangcm.sshy@sinopec.com

\# Corresponding author. Tel: +86-21-68462197; Fax: +86-21-68462283; E-mail: xzk@sinopec.com

This work was supported by the National Key Research and Development Program of China (2016YFB0701100, 2017YFB0702800), and the National Natural Science Foundation of China (21673295).

DOI: 10.1016/S1872-2067(18)63064-5 | http://www.sciencedirect.com/science/journal/18722067 | Chin. J. Catal., Vol. 39, No. 7, July 2018
} 
H-SAPO-18 with AEI framework topology also has moderate cages and small pore openings. Despite the same pore openings $(3.8 \times 3.8 \AA)$ of both CHA and AEI frameworks, the topologies are different, and the cage diameter varies by $\sim 0.3 \AA$, described by the largest included sphere $(7.05 \AA$ for AEI vs. $6.72 \AA$ for CHA). These differences may lead to slight changes in the product distribution and coking behavior compared to that of H-SAPO-34 for the MTO conversion [12-20].

In addition to light olefins as primary products, higher olefins, alkanes, and aromatics can be formed in the cavities of catalysts as well. The diverse distribution of products indicates that methanol involves complex reaction networks in MTO conversion [21-23]. It is now accepted that MTO conversion proceeds via the indirect hydrocarbon pool mechanism in zeolites or zeotypes, and the active center is composed of inorganic Brønsted acid sites and in-situ organic hydrocarbon pool species $[24,25]$. According to the nature of hydrocarbon pool species, two different catalytic cycles were proposed, namely the aromatic-based cycle and the olefin-based cycle [26-28]. In the aromatic-based cycle, polymethylbenzenes (MBs) were suggested as the active hydrocarbon pool, and both side chain and paring reaction pathways were previously suggested to split off light olefins [29-34]. In the olefin-based cycle, the higher olefins such tetramethylethene (TME) were suggested as the active hydrocarbon pool, which undergo methylation and cracking elementary steps [35-37]. Combining both the aromatic-based and olefin-based cycles is the so-called "dual cycle" concept first proposed by Svelle and other authors [38,39]. Both cycles are interconnected in the reaction. Regarding the contribution to the product selectivity, it has been found that ethene is selectively favored in the aromatic-based cycle, which is less favored in the olefin-based cycle $[38,40]$. As stated previously, both the aromatic-based and olefin-based cycles are mechanically similar, as both cycles involve the same sequence of elementary steps and the key is the formation of cracking precursors with alkyl chains for elimination [36,41]. Despite the clear depiction of the hydrocarbon pool mechanism, the dominant hydrocarbon pool species is still a subject of debate, and understanding the structural effects of zeolites and hydrocarbon pool species on MTO catalytic performance is a persistent challenge [42-48].

In addition to isotopic kinetic analysis, in-situ spectroscopy and operando spectroscopy, density functional theory (DFT) calculations have been indispensable in efforts to unravel the underlying chemistry of the MTO conversion [28,49,50]. The direct kinetic comparison of both aromatic-based and olefin-based cycles in H-ZSM-5 and H-SAPO-34 have suggested that the olefin-based cycle plays an important role to produce light olefins based on the energetic span model [36,51,52]. The aromatic-based cycle in H-SAPO-18 has been theoretically studied in periodic models with dispersion-corrected exchange correlation (XC) functional [53]. It is now in a positon to investigate the olefin-based cycle in H-SAPO-18 to understand the dominant hydrocarbon pool species by comparing the kinetics of both cycles.

\section{Computational details}

All periodic DFT calculations were performed using the Vienna Ab initio Simulation Package (VASP 5.3.5) [54]. The electron-ion interaction was described by the projector augmented wave (PAW) method [55,56]. The Bayesian error estimation functional with van der Waals (vdW) correlation (BEEF-vdW) was also employed [57]. The plane wave basis set kinetic energy cutoff was $400 \mathrm{eV}$. The sampling of the Brillouin zone was only with $\Gamma$ point. The dimer method was utilized to locate transition states [58]. A force threshold of $0.01 \mathrm{eV} / \AA ̊$ was used for the optimization of all structures. The harmonic frequency calculations employed a partial Hessian vibrational analysis (PHVA), including $\mathrm{H}$ atom of acidic sites and organic species part of the involved states. The zero point energies (ZPE), enthalpies, entropies, and Gibbs free energies were then calculated from harmonic frequencies [36]. The accuracy of the thermodynamics calculations using PHVA method was evaluated by comparing it to the results calculated using the FHVA (full Hessian vibrational analysis) method in H-SAPO-34 [36].

The H-SAPO-18 zeotype was modeled by periodic $48 \mathrm{~T}$ cell. One $\mathrm{P}$ atom at the $\mathrm{T} 2$ site was replaced by a $\mathrm{Si}$ atom in H-SAPO-18 to generate one Brønsted acid site in one supercell, which was located between $\mathrm{T} 2$ and $\mathrm{T} 1$ sites as it is the most stable site (Fig. 1) [59]. The lattice constants were optimized using a $800 \mathrm{eV}$ energy cutoff and a $0.01 \mathrm{eV} / \AA ̊$ force threshold (13.91, 12.87, $18.79 \AA$ for AlPO-18), similar to the experimental lattice constants $(13.71,12.73,18.57 \AA)$. The positions of all atoms were relaxed in the calculations, while the lattice constants were fixed at the optimized values.

\section{Results and discussion}

The adsorption of methanol at the acid site of zeolites is the first step to initiate the MTO conversion. As shown in Fig. 1, methanol is physiosorbed via hydrogen-bonding with the acid site of H-SAPO-18; the distance between the proton of acid site and the hydroxyl 0 atom is $1.57 \AA$. The adsorption enthalpy in H-SAPO-18 is calculated to be $-81 \mathrm{~kJ} / \mathrm{mol}$, which is very similar to that in H-SAPO-34 with the same composition and size of pore openings $(-80 \mathrm{~kJ} / \mathrm{mol})$ [36]. The adsorption enthalpies of methanol at other acid sites adjacent to different substituted $\mathrm{T}$ sites (T1, T2, or $\mathrm{T} 3$ ) by $\mathrm{Si}$ atom were calculated to range from -78 to $-82 \mathrm{~kJ} / \mathrm{mol}$, implying that methanol adsorption is less sensitive to the local environment in eight-membered SAPO zeotypes with moderate pore size.

In the olefin-based cycle, the olefins themselves serve as the hydrocarbon pool species for the growth of alkyl chains, which
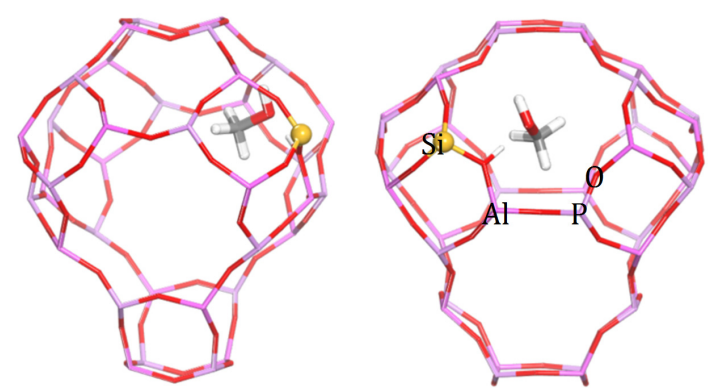

Fig. 1. Adsorption structure of methanol in H-SAPO-18. 


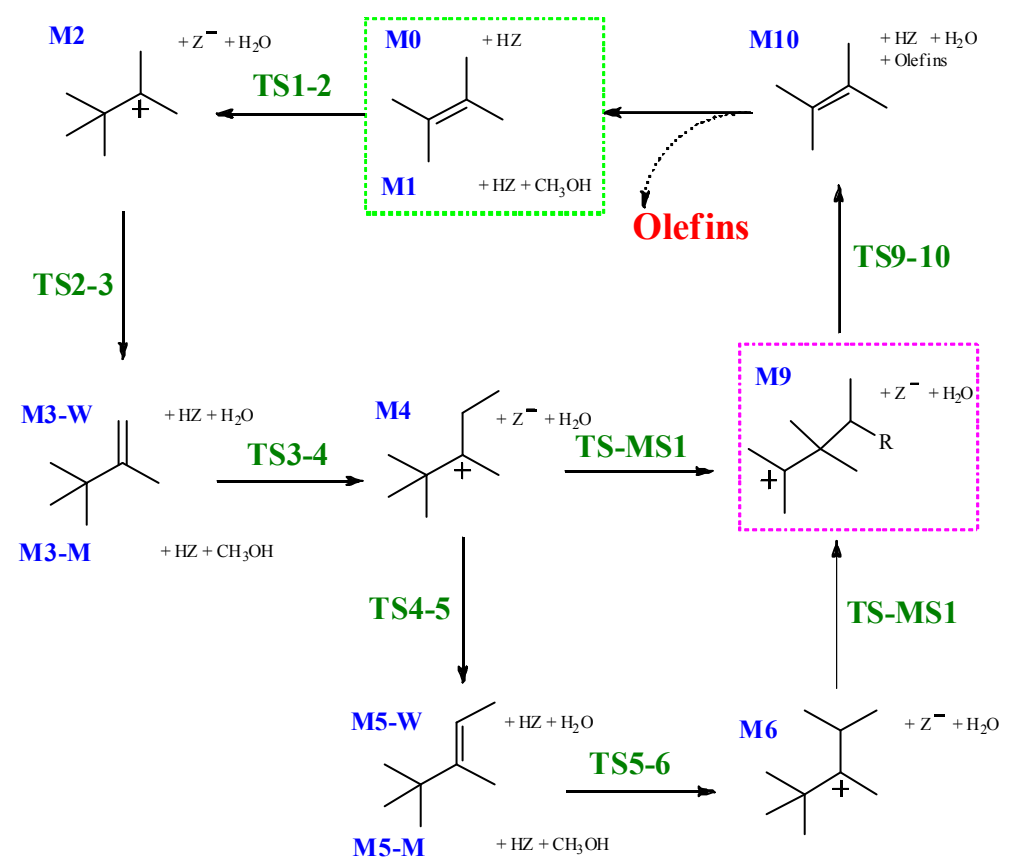

Scheme 1. Olefin-based cycle using TME as representative hydrocarbon pool species in zeolites (HZ) [36].

can finally be cracked into light olefins. The elementary steps in this cycle also includes the methylation of olefins, deprotonation, isomerization, and cracking of non-cyclic carbenium ions. TME was still selected as the representative hydrocarbon pool of olefins in H-SAPO-18 to address the kinetics of the olefin-based cycle. The detailed TME-based cycle is shown in Scheme 1, and the calculated Gibbs free energy reaction diagrams at $0 \mathrm{~K}$ and $673 \mathrm{~K}$ in H-SAPO-18 are shown in Fig. 2.

The adsorption enthalpy of TME is calculated and found to be $-85 \mathrm{~kJ} / \mathrm{mol}$ in H-SAPO-18, similar to that in H-SAPO-34 ($86 \mathrm{~kJ} / \mathrm{mol}$ ). As TME cannot diffuse out of the pores, it can only be formed in situ. With the presence of TME, the adsorption enthalpy of the first methanol is $-90 \mathrm{~kJ} / \mathrm{mol}$, which is higher than that of methanol adsorption in the absence of TME. This

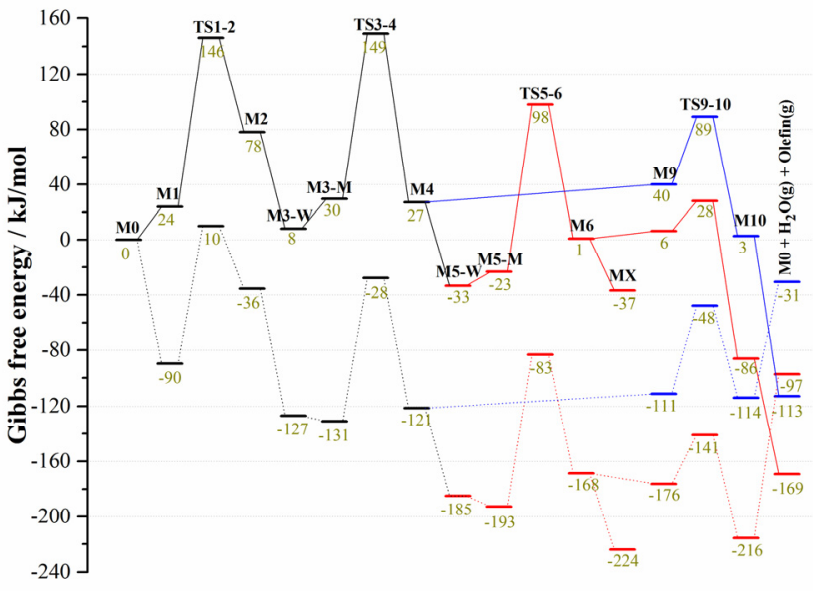

Fig. 2. Gibbs free energy diagram of the TME-based cycle in H-SAPO-18 at $0 \mathrm{~K}$ (dotted line) and $673 \mathrm{~K}$ (solid line). The cycle consists of alkyl chain propagation (in black), ethene elimination (in blue), and propene elimination (in red). methanol then attacks TME to form a tert-C7+ ion (M2) by overcoming an enthalpy barrier of $100 \mathrm{~kJ} / \mathrm{mol}$ in the first methylation step (M1 $\rightarrow$ TS1-2). The formed tert-C7+ ion is very unstable, which can easily be deprotonated into the corresponding C7 olefin (M3) with the assistance of water. The formation of higher C7 olefin from TME is exothermic by 37 $\mathrm{kJ} / \mathrm{mol}$. The desorption of water and adsorption of the second methanol then advances the propagation of higher olefins. The enthalpy barrier of the second methylation step (M3-M $\rightarrow$ TS3-4) is $103 \mathrm{~kJ} / \mathrm{mol}$. The formed C8 species may then undergo the cracking step to form light olefins or the methylation step to form C9 species. In the case of the third methylation step (M5-M $\rightarrow$ TS5-6), the enthalpy barrier is $109 \mathrm{~kJ} / \mathrm{mol}$. As shown in Fig. 3, the breaking $\mathrm{C}-\mathrm{O}$ bond distance and the forming $\mathrm{C}-\mathrm{C}$ bond distance at three methylation transition states are around 2.1 and $2.3 \AA$, respectively. From Fig. 2, the relative stabilities of the formed non-cyclic carbenium ions in H-SAPO-18 increase with the number of carbon atoms (M2 > M4 > M6); the enthalpy difference between carbenium ions and the corresponding olefins decreases from 91,64 , to $56 \mathrm{~kJ} / \mathrm{mol}$ for C7, C8, and C9 species at $0 \mathrm{~K}$, respectively.

The cracking elementary step is usually competitive with the methylation step for the higher olefins. Regarding the cracking of $\mathrm{C} 8+$ ion to produce ethene, the isomerization involving the shift of a methyl group forms the cracking precursor of tert-C8+ ion (M9); then the simultaneous breaking of the $\mathrm{C}-\mathrm{C}$ bond and deprotonation of the terminal methyl group assisted by water close one catalytic cycle to split off ethene. The enthalpy barrier for this step (M9 $\rightarrow$ TS9-10/C2) is only 63 $\mathrm{kJ} / \mathrm{mol}$, which is slightly lower than the enthalpy barrier in H-SAPO-34 (75 kJ/mol) [36]. Taking stable C8 olefin as the reference (M5-W), the enthalpy barrier of C8 cracking to ethene was calculated at $137 \mathrm{~kJ} / \mathrm{mol}$. In the case of cracking of C9+ 

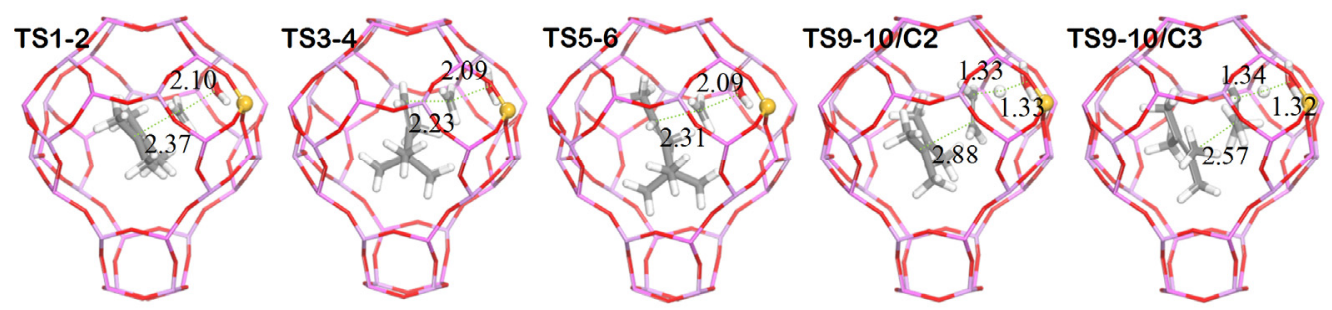

Fig. 3. Transition state structures in the TME-based cycle in H-SAPO-18. All distances are in $\AA$.

ion to produce propene, the enthalpy barrier is only $35 \mathrm{~kJ} / \mathrm{mol}$, which is lower than the enthalpy barrier in HSAPO-34 (54 $\mathrm{kJ} / \mathrm{mol}$ ) [36]. Taking C9 olefin as the reference (MX), the enthalpy barrier of $\mathrm{C} 9$ cracking is $83 \mathrm{~kJ} / \mathrm{mol}$.

The barrier dependence of the elementary step on acid sites was evaluated using the methylation of TME with methanol. As listed in Table S1, the enthalpy barriers were calculated to range from 88 to $94 \mathrm{~kJ} / \mathrm{mol}$ at other acid sites, which is slightly lower than the above calculated value $(100 \mathrm{~kJ} / \mathrm{mol})$. These results suggest that the enthalpy barrier calculated at the most stable acid site may represent the upper limit for each elementary step in H-SAPO-18. In addition, the uncertainty related to the enthalpy barrier was estimated by the BEEF-vdW ensemble, and a relative error of around $20 \%$ was predicted for the involved elementary methylation and cracking steps (Fig. S1).

At the MTO reaction temperature $(673 \mathrm{~K})$, the Gibbs free energy barriers for three methylation steps are around 120 $\mathrm{kJ} / \mathrm{mol}$, which is higher than those in H-SAPO-34 by about $15-30 \mathrm{~kJ} / \mathrm{mol}$ [36]. The substitution of water by methanol (M3-W $\rightarrow$ M3-M, M5-W $\rightarrow$ M5-M) requires extra energy due to the weak acidity of H-SAPO-18. The Gibbs free energy barriers for the cracking of $\mathrm{C} 8+$ and $\mathrm{C} 9+$ ions to ethene and propene are only 49 and $22 \mathrm{~kJ} / \mathrm{mol}$, which are 122 and $65 \mathrm{~kJ} / \mathrm{mol}$ when taking the most stable C8 or C9 olefins as the reference. It should be noted that both barriers are 185 and $157 \mathrm{~kJ} / \mathrm{mol}$ in H-SAPO-34 [36]. From Fig. 2, it appears that the methylation of higher olefins is more energy demanding than the subsequent cracking steps in the TME-based cycle. The overall Gibbs free energy barrier in the TME-based cycle is therefore less than $150 \mathrm{~kJ} / \mathrm{mol}$ at $673 \mathrm{~K}$ in H-SAPO-18. The framework topology strongly influences the kinetics of the elementary steps in MTO conversion. Regarding the TME-based cycle, it is the cracking of higher olefins that are rate-determining in H-SAPO-34, while it is the methylation of olefins that are rate-determining in H-SAPO-18. In addition, the stability of carbenium ions increases with temperature; the free energy differences between carbenium ions and the corresponding olefins are 70,60, and $38 \mathrm{~kJ} / \mathrm{mol}$ for C7, C8, and C9 species at $673 \mathrm{~K}$, respectively.

We have systematically studied the aromatic-based cycle in H-SAPO-18 [53], and suggested that hexamethylbenzene (HMB) was the dominant component of MBs evaluated from static adsorption enthalpy and interconversion thermodynamics. The overall Gibbs free energy barriers of MBs-based cycles were calculated to be greater than $200 \mathrm{~kJ} / \mathrm{mol}$ at $673 \mathrm{~K}$. By directly comparing the kinetics of both MBs-based cycle and TME-based cycle, we conclude that the olefin-based cycle dominates the MTO conversion in H-SAPO-18. It is olefins themselves rather than the aromatics that are likely to be the dominant active hydrocarbon pool for MTO conversion. It should be noted that the olefinic hydrocarbon pool is not limited to TME, as the methylation of higher olefins is feasible and any olefins that can be methylated could serve as the hydrocarbon pool. In addition, higher branched olefins hardly diffuse out of zeolites or zeotypes with eight-membered rings, and the concentration of which is expected to be high. Previous experimental results found that propene and butenes were predominantly formed in H-SAPO-18 and H-SAPO-34, and butenes were more prominent in H-SAPO-18 than in H-SAPO-34 [17]. This appears to be consistent with the theoretical results that olefins act as the dominant hydrocarbon pool in both zeotypes, as ethene is selectively favored in the aromatic-based cycle.

In both the aromatic-based and olefin-based cycles, methylation and cracking are the two most important elementary steps for alkyl chain propagation and elimination. The methylation and cracking steps in the olefin-based cycle in H-SAPO-18 are now addressed. In the methylation step, we assumed that methanol was first adsorbed at the acid site, then olefin was co-adsorbed in the cage of H-SAPO-18. The adsorption enthalpy of olefins with the absence of methanol is listed in Table 1 . The adsorption enthalpy increases monotonously with the size of olefins; it increases by $\sim 15 \mathrm{~kJ} / \mathrm{mol}$ when one $\mathrm{CH}_{2}$ unit is added to the chain from propene. Two different reaction barriers can be derived according to the reference state in the methylation, namely, an apparent enthalpy barrier and an intrinsic enthalpy barrier. Both enthalpy barriers have been systematically studied in a range of zeolites, including H-ZSM-5, H-SAPO-34, H-ZSM-22, and H-ZSM-58 using cluster or periodic models $[60,61]$. Both values for a series of olefins from ethene to hexene (TME) in H-SAPO-18 are listed in Table 1. The correspond-

Table 1

Calculated adsorption enthalpy of olefins with the absence of methanol at acid site, and calculated apparent and intrinsic enthalpy barriers of olefin methylation in H-SAPO-18 at $0 \mathrm{~K}$. BEEF-vdW ensemble error estimates for intrinsic barriers are listed. The unit is $\mathrm{kJ} / \mathrm{mol}$.

\begin{tabular}{lccc}
\hline & $\begin{array}{c}\text { Adsorption enthalpy of } \\
\text { olefins }\end{array}$ & $\begin{array}{c}\text { Apparent } \\
\text { barrier }\end{array}$ & $\begin{array}{c}\text { Intrinsic } \\
\text { barrier }\end{array}$ \\
\hline ethene/C2 & -27 & 114 & $148 \pm 25$ \\
propene/C3 & -39 & 76 & $123 \pm 27$ \\
1-butene/C4-1 & -55 & 67 & $130 \pm 21$ \\
2-butene/C4-2 & -55 & 58 & $121 \pm 21$ \\
iso-butene/C4-iso & -55 & 50 & $113 \pm 21$ \\
iso-pentene/C5 & -70 & 28 & $108 \pm 21$ \\
TME/C6 & -85 & 5 & $100 \pm 21$ \\
\hline
\end{tabular}



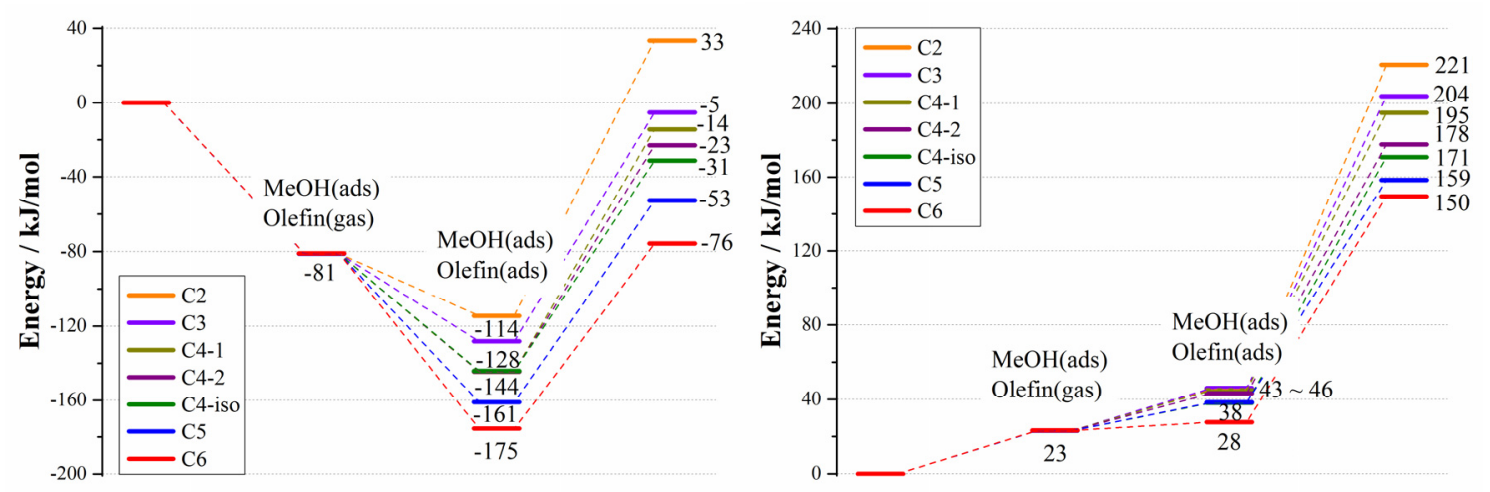

Fig. 4. Gibbs free energy diagram of the olefin methylation in H-SAPO-18 at $0 \mathrm{~K}$ (a) and $673 \mathrm{~K}$ (b).

ing Gibbs free energy diagram at 0 and $673 \mathrm{~K}$ in H-SAPO-18 is presented in Fig. 4.

Generally, the intrinsic enthalpy barrier relates to the branching degree of the double bond. The intrinsic enthalpy barrier for the methylation of ethene is as high as $148 \mathrm{~kJ} / \mathrm{mol}$, and that of TME is $100 \mathrm{~kJ} / \mathrm{mol}$. The apparent enthalpy barrier is usually applied for comparison to the experimental results. As listed in Table 1, the apparent methylation barriers of ethene, propene, and 2-butene in H-SAPO-18 are 114, 76, and 58 $\mathrm{kJ} / \mathrm{mol}$ respectively, much higher than those in H-SAPO-34 (76, 34 , and $28 \mathrm{~kJ} / \mathrm{mol}$ ) [35]. With the size increase of olefins, the apparent enthalpy barrier of TME is only $5 \mathrm{~kJ} / \mathrm{mol}$.

At $673 \mathrm{~K}$, the co-adsorption free energies of methanol and olefins span from 28 to $46 \mathrm{~kJ} / \mathrm{mol}$; the range is less than 20 $\mathrm{kJ} / \mathrm{mol}$, much less than that at $0 \mathrm{~K}(\sim 60 \mathrm{~kJ} / \mathrm{mol},-175 \sim-114$ $\mathrm{kJ} / \mathrm{mol}$ ). This indicates that the stabilities of higher olefins are more sensitive to temperature than lower olefins due to the entropy effect. However, the span is $\sim 70 \mathrm{~kJ} / \mathrm{mol}(-150 \sim-221$ $\mathrm{kJ} / \mathrm{mol}$ ) for the free energies of the transition states at $673 \mathrm{~K}$. The dependence of this span on temperature is not obvious as that of co-adsorption intermediates. With respect to the gaseous olefins and methanol, the overall free energy barriers are over $190 \mathrm{~kJ} / \mathrm{mol}$ for the methylation of ethene, propene, and 1-butene in H-SAPO-18 and less than $180 \mathrm{~kJ} / \mathrm{mol}$ for the methylation of 2-butene, iso-butene, iso-pentene, and TME. The methylation of olefins is therefore very feasible in H-SAPO-18 at the MTO reaction temperature; the higher olefins, especially olefins with three or four branched alkyl chains, are very readily attacked by adsorbed methanol.

In scheme 1, we assume that the C8+ ion eliminates ethene and the $\mathrm{C} 9+$ ion splits off propene in order to regenerate the original hydrocarbon pool TME. In fact, other lower olefins may be produced from higher non-cyclic carbenium ions by surmounting different barriers. As ethene and propene are the two preferred olefin products in H-SAPO-18, the cracking kinetics of non-cyclic carbenium ions from $\mathrm{C} 5+$ ion to $\mathrm{C} 9+$ ion were studied. The enthalpy barriers were calculated with respect to the co-adsorption of water and stable olefins in H-SAPO-18 (Fig. 5). The corresponding error was estimated by the BEEF-vdW ensemble as shown in Fig. S1. Water was employed to assist the proton shift between organic intermediates and the framework $[30,34]$. The optimized transition state structures are shown in
Fig. 6. The cracking enthalpy barrier of the $\mathrm{C} 5+$ ion to ethene and propene is as high as $197 \mathrm{~kJ} / \mathrm{mol}$, indicating that the direct cracking of the $\mathrm{C} 5+$ ion is not likely in H-SAPO-18. The cracking enthalpy barrier of the $\mathrm{C} 6+$ ion to produce propene is 161 $\mathrm{kJ} / \mathrm{mol}$, which is slightly lower than that to produce ethene $(170 \mathrm{~kJ} / \mathrm{mol})$. In the case of cracking the $\mathrm{C} 7+$ ion, the enthalpy barriers are calculated to be 139 and $157 \mathrm{~kJ} / \mathrm{mol}$ to produce propene and ethene, respectively. Regarding the cracking of the C8+ ion, the enthalpy barrier to produce propene is only 105 $\mathrm{kJ} / \mathrm{mol}$, much lower than that to produce ethene by $\sim 30$ $\mathrm{kJ} / \mathrm{mol}(137 \mathrm{~kJ} / \mathrm{mol})$.

Interestingly, the enthalpy barriers of cracking step assisted by water were found to linearly scale with the number of carbon atoms of cracking precursors like higher olefins or carbenium ions. As shown in Fig. 5, the enthalpy barriers decrease by about 19 and $27 \mathrm{~kJ} / \mathrm{mol}$, with the number of carbon atoms to produce ethene and propene, respectively, indicating that the cracking barrier to produce propene is more sensitive to the size of precursors. The linear scaling relationships for the corresponding free energy barriers at $673 \mathrm{~K}$ can be observed as shown in Fig. S2. The formation of ethene therefore becomes more unfavorable as the size of precursors increase. As addressed previously from a reaction point of view, the olefin selectivity is controlled by the distribution of cracking precur-

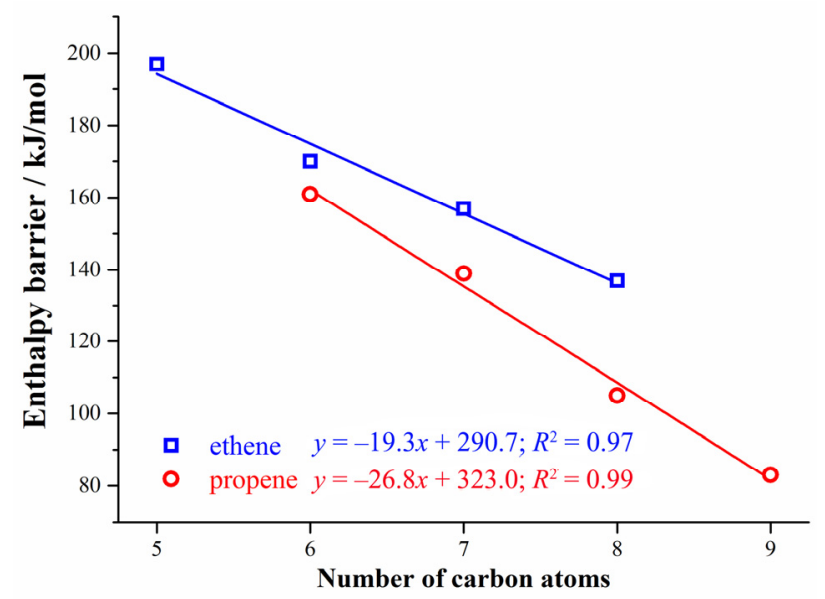

Fig. 5. Calculated enthalpy barriers in the cracking of higher olefins (from C5 to C9) to produce ethene (in blue) or propene (in red) with the assistance of water in H-SAPO-18 at $0 \mathrm{~K}$. 

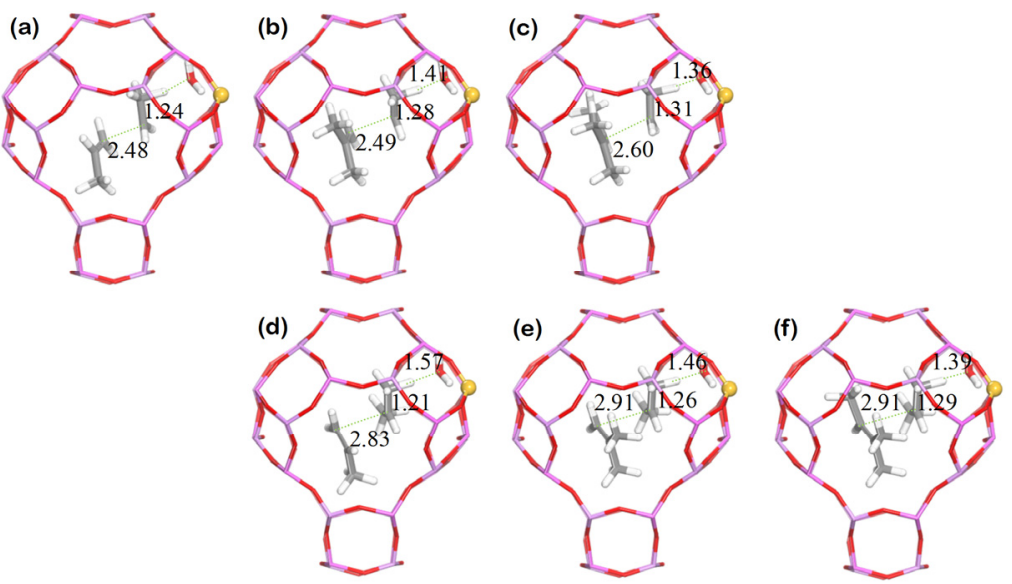

Fig. 6. Optimized transition state structures in the cracking of higher olefins to produce ethene (a-c) or propene (d-f) with the assistance of water in H-SAPO-18. All distances are in $\AA$.

sors, which can be tailored by the catalyst structure and reaction conditions in the olefin-based cycle [35].

Finally, we further highlight the similarity between the olefin-based cycle and the aromatic-based cycle. Both cycles undergo alkyl chain propagation and elimination/cracking steps to produce light olefins. Table 2 lists the important intermediates involved in both the aromatic HMB-based cycle and the olefinic TME-based cycle. The differences between the intermediates in the HMB-based cycle and the TME-based cycle were found to be invariant. Linking two terminal methyl groups of intermediates in the TME-based cycle with a C6 motif results in the corresponding intermediates in HMB-based cycle. So do the transition states between the two cycles. An extra steric effect would be exposed in the states involved in the HMB-based cycle and may explain the higher overall free energy barriers in the HMB-based cycle compared to the

\section{Table 2}

Similarity of the involved important intermediates between the aromatic HMB-based cycle and the olefinic TME-based cycle. An invariant C6-based motif (in grey color) links two corresponding intermediates.

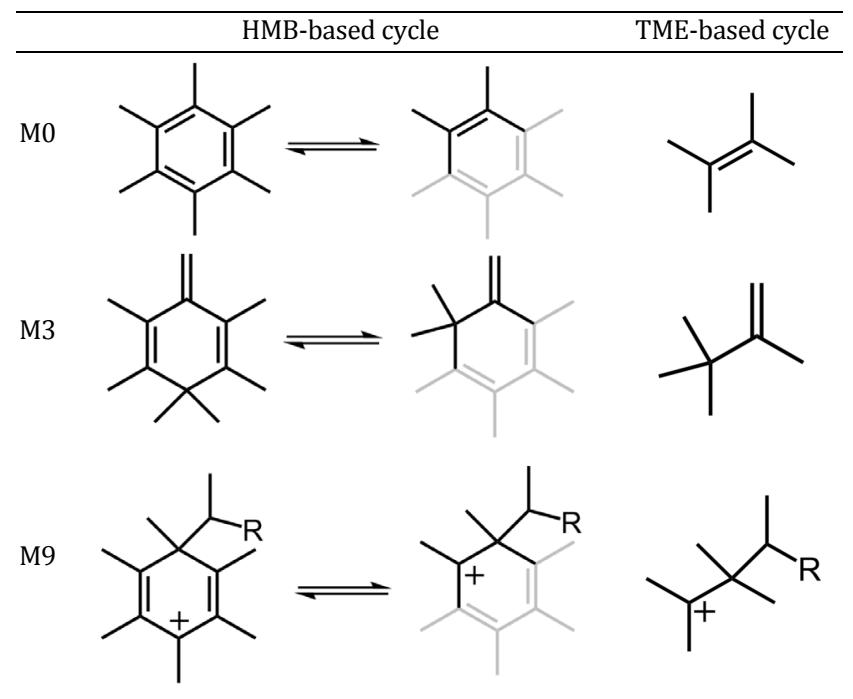

TME-based cycle.

\section{Conclusions}

The preferred reaction mechanism of the MTO conversion in H-SAPO-18 was studied using periodic DFT calculations. Using TME as the representative hydrocarbon pool in the olefin-based cycle, the overall free energy barrier was calculated to be less than $150 \mathrm{~kJ} / \mathrm{mol}$ in the TME-based cycle at $673 \mathrm{~K}$, which is much lower than that in the aromatic-based cycle $(200$ $\mathrm{kJ} / \mathrm{mol}$ ), indicating that olefins themselves are the dominant hydrocarbon pool species in H-SAPO-18. The olefin-based cycle is mechanically similar to the aromatic-based cycle; both cycles involve similar intermediate and transition state structures and the same sequence of elementary steps. The methylation and cracking are two important elementary steps in MTO conversion. Interestingly, the cracking barrier linearly decreases with the number of carbon atoms in cracking precursors; the production of ethene is much less favored for the cracking of higher precursors from a reaction perspective. The results in this study further highlight the importance of the olefin-based cycle in MTO conversion catalyzed by eight-membered SAPO zeotypes and revealed the similarity between the olefin-based cycle and the aromatic-based cycle. We believe that it is essential to have a clear picture of the distribution of cracking precursors to address the effect of catalyst structure and reaction conditions on MTO conversion.

\section{References}

[1] G. A. Olah, Angew. Chem. Int. Ed., 2013, 52, 104-107.

[2] C. Mesters, Annu. Rev. Chem. Biomol. Eng., 2016, 7, 223-238.

[3] C. D. Chang, A. J. Silvestri, J. Catal., 1977, 47, 249-259.

[4] M. Stocker, Micro. Meso. Mater., 1999, 29, 3-48.

[5] F. J. Keil, Micro. Meso. Mater., 1999, 29, 49-66.

[6] P. Tian, Y. X. Wei, M. Ye, Z. M. Liu, ACS Catal., 2015, 5, 1922-1938.

[7] M. Behrens, F. Studt, I. Kasatkin, S. Kühl, M. Hävecker, F. Abild-Pedersen, S. Zander, F. Girgsdies, P. Kurr, B. L. Kniep, M. 


\section{Graphical Abstract}

Chin. J. Catal., 2018, 39: 1272-1279 doi: 10.1016/S1872-2067(18)63064-5

Elucidating the dominant reaction mechanism of methanol-to-olefins conversion in H-SAPO-18: A first-principles study

Chuan-Ming Wang *, Yang-Dong Wang, Zai-Ku Xie * SINOPEC Shanghai Research Institute of Petrochemical Technology,

The olefins were calculated to be the dominant hydrocarbon pool for MTO conversion in H-SAPO-18. The enthalpy barrier of the cracking step linearly relates to the size of cracking precursors.

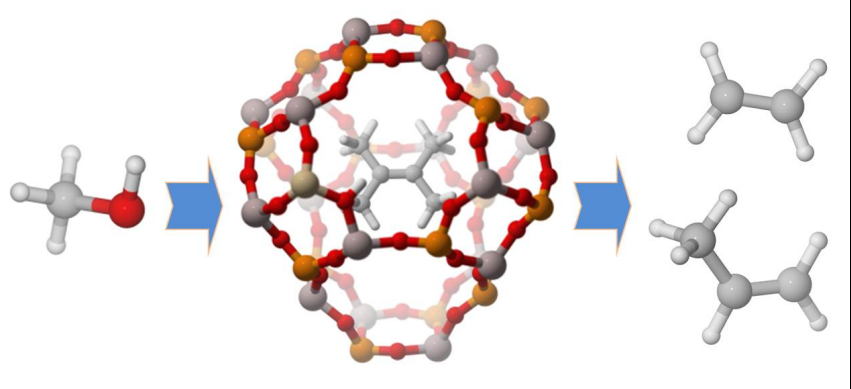

Tovar, R. W. Fischer, J. K. Norskov, R. Schloegl, Science, 2012, 336, 893-897.

[8] H. O. Pastore, S. Coluccia, L. Marchese, Annu. Rev. Mater. Res., 2005, 35, 351-395.

[9] W. L. Dai, X. Wang, G. J. Wu, N. J. Guan, M. Hunger, L. D. Li, ACS Catal., 2011, 1, 292-299.

[10] I. Pinilla-Herrero, U. Olsbye, C. Márquez-Álvarez, E. Sastre, J. Catal., 2017, 352, 191-207.

[11] B. M. Lok, C. A. Messina, R. L. Patton, R. T. Gajek, T. R. Cannan, E. M. Flanigen, J. Am. Chem. Soc., 1984, 106, 6092-6093.

[12] J. S. Chen, P. A. Wright, J. M. Thomas, S. Natarajan, L. Marchese, S. M. Bradley, G. Sankar, C. R. A. Catlow, P. L. Gai-Boyes, R. P. Townesnd, C. M. Lo, J. Phys. Chem., 1994, 98, 10216-10224.

[13] R. Wendelbo, D. Akporiaye, A. Andersen, I. M. Dahl, H. B. Mostad, App. Catal. A, 1996, 142, L197-L207.

[14] M. A. Djieugoue, A. M. Prakash, L. Kevan, J. Phys. Chem. B, 2000, 104, 6452-6461.

[15] A. G. Gayubo, A. T. Aguayo, A. Alonso, A. Atutxa, J. Bilbao, Catal. Today, 2005, 106, 112-117.

[16] J. R. Chen, J. Z. Li, C. Y. Yuan, S. T. Xu, Y. X. Wei, Q. Y. Wang, Y. Zhou, J. B. Wang, M. Z. Zhang, Y. L. He, S. L. Xu, Z. M. Liu, Catal. Sci. Technol., 2014, 4, 3268-3277.

[17] J. R. Chen, J. Z. Li, Y. X. Wei, C. Y. Yuan, B. Li, S. T. Xu, Y. Zhou, J. B. Wang, M. Z. Zhang, Z. M. Liu, Catal. Commun., 2014, 46, 36-40.

[18] M. Nazari, G. Moradi, R. M. Behbahani, M. Ghavipour, S. Abdollahi, Catal. Lett., 2015, 145, 1893-1903.

[19] M. Dusselier, M. A. Deimund, J. E. Schmidt, M. E. Davis, ACS Catal., 2015, 5, 6078-6085.

[20] R. Martínez-Franco, Z. B. Li, J. Martínez-Triguero, M. Moliner, A. Corma, Catal. Sci. Technol., 2016, 6, 2796-2806.

[21] J. F. Haw, W. G. Song, D. M. Marcus, J. B. Nicholas, Acc. Chem. Res., 2003, 36, 317-326

[22] U. Olsbye, S. Svelle, M. Bjorgen, P. Beato, T. V. W. Janssens, F. Joensen, S. Bordiga, K. P. Lillerud, Angew. Chem. Int. Ed., 2012, 51, 5810-5831.

[23] S. Ilias, A. Bhan, ACS Catal., 2013, 3, 18-31.

[24] W. G. Song, J. F. Haw, J. B. Nicholas, C. S. Heneghan, J. Am. Chem. Soc., 2000, 122, 10726-10727.

[25] B. Arstad, S. Kolboe, J. Am. Chem. Soc., 2001, 123, 8137-8138.

[26] U. Olsbye, M. Bjorgen, S. Svelle, K. P. Lillerud, S. Kolboe, Catal. Today, 2005, 106, 108-111.

[27] K. Hemelsoet, J. Van der Mynsbrugge, K. De Wispelaere, M. Waroquier, V. Van Speybroeck, ChemPhysChem, 2013, 14, 1526-1545.
[28] V. Van Speybroeck, K. De Wispelaere, J. Van der Mynsbrugge, M. Vandichel, K. Hemelsoet, M. Waroquier, Chem. Soc. Rev., 2014, 43, 7326-7357.

[29] D. M. McCann, D. Lesthaeghe, P. W. Kletnieks, D. R. Guenther, M. J. Hayman, V. Van Speybroeck, M. Waroquier, J. F. Haw, Angew. Chem. Int. Ed., 2008, 47, 5179-5182.

[30] C. M. Wang, Y. D. Wang, Z. K. Xie, Z. P. Liu, J. Phys. Chem. C, 2009 113, 4584-4591.

[31] D. Lesthaeghe, A. Horre, M. Waroquier, G. B. Marin, V. Van Speybroeck, Chem. Eur. J., 2009, 15, 10803-10808.

[32] C. M. Wang, Y. D. Wang, H. X. Liu, Z. K. Xie, Z. P. Liu, J. Catal., 2010 271, 386-391.

[33] C. M. Wang, Y. D. Wang, H. X. Liu, Z. K. Xie, Z. P. Liu, Micro. Meso. Mater., 2012, 158, 264-271.

[34] K. De Wispelaere, K. Hemelsoet, M. Waroquier, V. Van Speybroeck, J. Catal., 2013, 305, 76-80.

[35] C. M. Wang, Y. D. Wang, Z. K. Xie, J. Catal., 2013, 301, 8-19.

[36] C. M. Wang, Y. D. Wang, Y. J. Du, G. Yang, Z. K. Xie, Catal. Sci. Technol., 2015, 5, 4354-4364.

[37] D. Lesthaeghe, J. Van der Mynsbrugge, M. Vandichel, M. Waroquier, V. Van Speybroeck, ChemCatChem, 2011, 3, 208-212.

[38] S. Svelle, F. Joensen, J. Nerlov, U. Olsbye, K. P. Lillerud, S. Kolboe, M. Bjorgen, J. Am. Chem. Soc., 2006, 128, 14770-14771.

[39] M. Bjorgen, S. Svelle, F. Joensen, J. Nerlov, S. Kolboe, F. Bonino, L. Palumbo, S. Bordiga, U. Olsbye, J. Catal., 2007, 249, 195-207.

[40] C. M. Wang, Y. D. Wang, Z. K. Xie, Catal. Sci. Technol., 2014, 4, 2631-2638.

[41] C. M. Wang, Y. D. Wang, Z. K. Xie, Chin. J. Chem . 2018, 36, 381-386.

[42] A. Hwang, D. Prieto-Centurion, A. Bhan, J. Catal., 2016, 337, 52-56.

[43] E. Borodina, H. Sharbini Harun Kamaluddin, F. Meirer, M. Mokhtar, A. M. Asiri, S. A. Al-Thabaiti, S. N. Basahel, J. Ruiz-Martinez, B. M. Weckhuysen, ACS Catal., 2017, 7, 5268-5281.

[44] W. L. Dai, G. Cao, L. Yang, G. J. Wu, M. Dyballa, M. Hunger, N. J. Guan, L. D. Li, Catal. Sci. Technol., 2017, 7, 607-618.

[45] M. Z. Zhang, S. T. Xu, Y. X. Wei, J. Z. Li, J. B. Wang, W. N. Zhang, S. S. Gao, Z. M. Liu, Chin. J. Catal., 2016, 37, 1413-1422.

[46] J. B. Wang, J. Z. Li, S. T. Xu, Y. C. Zhi, Y. X. Wei, Y. L. He, J. R. Chen, M. Z. Zhang, Q. Y. Wang, W. N. Zhang, X. Q. Wu, X. W. Guo, Z. M. Liu, Chin. J. Catal., 2015, 36, 1392-1402.

[47] H. Ma, Y. Y. Chen, S. Wang, Z. H. Wei, Z. F. Qin, M. Dong, J. F. Li, W. B. Fan, J. G. Wang, Catal. Sci. Technol., 2018, 8, 521-533.

[48] S. Wang, Y. Y. Chen, Z. H. Wei, Z. F. Qin, H. Ma, M. Dong, J. F. Li, W. B. Fan, J. G. Wang, J. Phys. Chem. C, 2015, 119, 28482-28498. 
[49] V. Van Speybroeck, K. Hemelsoet, L. Joos, M. Waroquier, R. G. Bell, C. R. A. Catlow, Chem. Soc. Rev., 2015, 44, 7044-7111.

[50] G. Sastre, Front. Chem. Sci. Eng., 2016, 10, 76-89.

[51] C. M. Wang, Y. D. Wang, Y. J. Du, G. Yang, Z. K. Xie, Catal. Sci. Technol., 2016, 6, 3279-3288.

[52] S. Kozuch, S. Shaik, Acc. Chem. Res., 2010, 44, 101-110.

[53] C. M. Wang, Y. D. Wang, H. X. Liu, Y. J. Du, G. Yang, Z. K. Xie, Chin. J. Catal., 2015, 36, 1573-1579.

[54] G. Kresse, J. Furthmuller, Phys. Rev. B, 1996, 54, 11169-11186.

[55] G. Kresse, D. Joubert, Phys. Rev. B, 1999, 59, 1758-1775.

[56] P. E. Blochl, Phys. Rev. B, 1994, 50, 17953-17979.
[57] J. Wellendorff, K. T. Lundgaard, A. Møgelhøj, V. Petzold, D. D. Landis, J. K. Nørskov, T. Bligaard, K. W. Jacobsen, Phys. Rev. B, 2012, 85, 235149.

[58] G. Henkelman, H. Jonsson, J. Chem. Phys., 1999, 111, 7010-7022.

[59] C. M. Wang, R. Y. Brogaard, Z. K. Xie, F. Studt, Catal. Sci. Technol., 2015, 5, 2814-2820.

[60] J. Van der Mynsbrugge, J. De Ridder, K. Hemelsoet, M. Waroquier, V. Van Speybroeck, Chem. Eur. J., 2013, 19, 11568-11576.

[61] V. Van Speybroeck, J. Van der Mynsbrugge, M. Vandichel, K. Hemelsoet, D. Lesthaeghe, A. Ghysels, G. B. Marin, M. Waroquier, J. Am. Chem. Soc., 2011, 133, 888-899.

\title{
H-SAPO-18催化甲醇制烯烃反应机理：第一性原理计算研究
}

\author{
王传明", 王仰东, 谢在库 \\ 中国石油化工股份有限公司上海石油化工研究院, 上海201208
}

\begin{abstract}
摘要: 低碳烯烃(乙烯、丙烯等)是重要的基本有机原料,一般通过蒸汽裂解或催化裂解生成得到。基于中国的资源结构特 点, 发展非石油资源路线合成低碳烯烃具有重要的战略意义. 其中从煤、天然气等资源出发, 通过甲醇合成低碳烯烃就提 供了这样一条可替代的路线. 因此分子節催化甲醇制烯烃(MTO)反应在过去几十年获得了广泛的关注和研究. 为了获得 高的产物选择性, 一般要求MTO分子篮催化材料具有较小的孔道结构以及合适的笼结构, H-SAPO-34和H-SAPO-18分子篮 就具有这样的空间结构特点. 但是MTO催化反应产物分布多样复杂, 因此需要深入认识MTO催化反应机理, 从而优化设计 分子篮结构和反应条件.

目前已经形成的共识认为, MTO催化反应沿着烃池反应机理进行, 但是烃池活性中心的结构还存在很多争议. 我们曾 系统研究了 H-SAPO-18分子篮中多甲基苯的分布, 以及催化MTO反应的芳烃循环路线, 指出多甲基苯路线的总吉布斯自由 能垒高于 $200 \mathrm{~kJ} / \mathrm{mol}(673 \mathrm{~K})$. 本文以四甲基乙烯(TME)作为代表性的烯烃烃池活性中心, 系统研究了 H-SAPO-18分子篮催 化MTO反应的烯烃循环路线. TME循环路线的总吉布斯自由能垒不大于 $150 \mathrm{~kJ} / \mathrm{mol}$, 远小于芳烃循环的总能垒. 因此, 烯烃 本身有很大可能是H-SAPO-18催化MTO反应的烃池活性中心. 我们也指出了芳烃循环和烯烃循环路线的相似性, 这包括 基元反应的相似性和中间体结构的相似性. 或者可以说, 芳烃循环和烯烃循环路线机理上没有区别, 关键是为了得到具有 烷基(侧)链的裂解前驱体, 最后通过裂解生成低碳烯烃. 在烯烃循环路线中, 产物选择性与裂解前驱体(高碳烯烃、碳正离 子等)的分布以及裂解动力学有关. 计算发现生成乙烯和丙烯的裂解基元反应能垒与裂解前驱体的碳数之间存在线性关 系. 本文进一步强调了分子篮催化MTO反应中烯烃活性中心的重要性, 并且清楚指出了烯烃循环和芳烃循环的机理相似 性.
\end{abstract}

关键词: 甲醇制烯烃；烃池机理；烯烃烃池；密度泛函理论；H-SAPO-18分子篮

收稿日期: 2018-01-18. 接受日期: 2018-03-21. 出版日期: 2018-07-05.

*通讯联系人. 电话: (021)68462197; 传真: (021)68462283; 电子信箱: wangcm.sshy@sinopec.com

\#通讯联系人. 电话: (021)68462197; 传真: (021)68462283; 电子信箱: xzk@sinopec.com

基金来源: 国家重点研发计划(2016YFB0701100, 2017YFB0702800); 国家自然科学基金(21673295).

本文的电子版全文由Elsevier出版社在ScienceDirect上出版(http://www.sciencedirect.com/science/journal/18722067). 